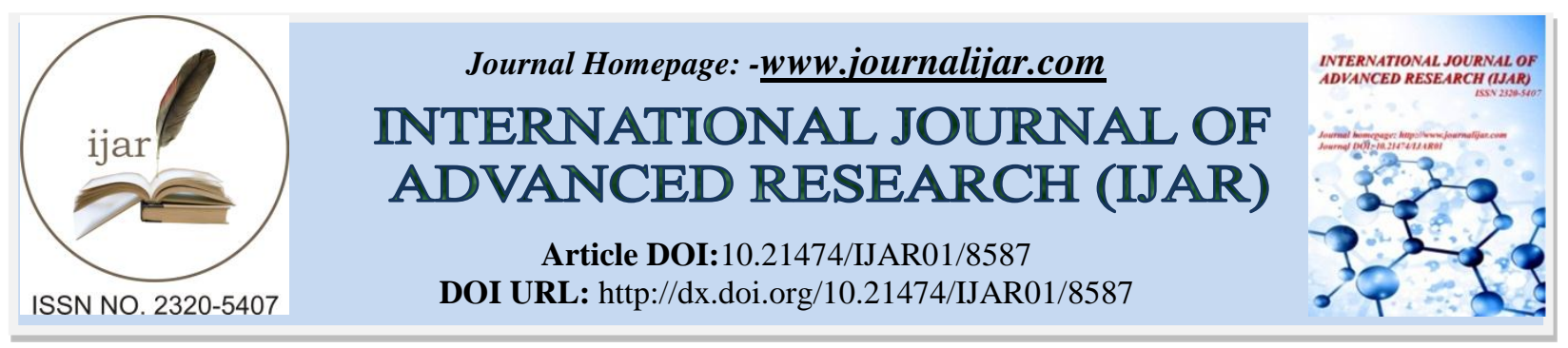

RESEARCH ARTICLE

\title{
MATERNAL AND FETAL OUTCOME AMONG PREGNANT WOMEN PRESENTING WITH HYPOTHYROIDISM.
}

Ashok Verma ${ }^{1}$, Dipen Parekh ${ }^{2}$, Meenakshi Verma ${ }^{3}$, Suresh Verma ${ }^{4}$, Ruchi Shah ${ }^{5}$ and Kranti Bishat ${ }^{5}$.

1. M.D (OBG),Associate Professor,Department of Obstetrics \& Gynecology,Dr Rajendera Prasad GovernmentMedicalCollege Kangra,Himachal Pradesh.

2. M.S (OBG),Medical Officer, Department of Obstetrics \& Gynecology,Dr Rajendera Prasad Government Medical College Kangra.

3. M.S (OBG),Senior Resident, Department of Obstetrics \& Gynecology,Dr Rajendera Prasad Government Medical College Kangra.

4. M.D (OBG),Professor \& Head, Department of Obstetrics \& Gynecology,Dr Rajendera Prasad Government Medical College Kangra.

5. M.B.B.S,Junior Resident (OBG), Department of Obstetrics \& Gynecology,Dr Rajendera Prasad Government Medical College Kangra.

\section{Manuscript Info}

\section{Manuscript History}

Received: 14 December 2018

Final Accepted: 16 January 2019

Published: February 2019

Key words:pregnancy; $\quad$ hypothyroidism; maternal morbidity; neonatal morbidity; thyroid screening.

\section{Abstract}

Background:Thyroid disorder is the second most common endocrine disorder affecting women of reproductive age. The increased prevalence of thyroid dysfunction in pregnancy and the need for proper management to reduce obstetrical and neonatal adverse events led us to collect the baseline data on hypothyroidism in pregnancy in our population.

Material and methods: A total of 1203 consecutive pregnant women attending antenatal clinic in our hospital and consented to participate were studied. All women were tested for TSH levels (determined by chemiluminescent enzyme immunoassay). Women having higher than normal range of $\mathrm{TSH}(>2.5 \mathrm{mIU} / \mathrm{L}$ in first trimester and $>3.0 \mathrm{mIU} / \mathrm{L}$ in second trimester were further tested with repeat TSH \& $\mathrm{T} 4$.

Results: 118 (9.8\%) were found to be hypothyroid. The mean age of the women was $26.2 \pm 3$.7years. $21.2 \%$ women had history of previous one or more spontaneous abortions, $15.3 \%$ had history of infertility. Symptoms of hypothyroidism were present in $33.9 \%$ women, $4.2 \%$ women had goiter. Mean BMI was $26.1 \mathrm{~kg} / \mathrm{m} 2.72 .9 \%$ were newly diagnosed in current pregnancy and $27.1 \%$ were known cases of hypothyroidism. $18.1 \%$ women had pregnancy induced hypertension, $11.9 \%$ had preterm labor, and $10.2 \%$ each had placental abruption and premature rupture of membranes. $7.6 \%$ women had intrauterine growth restriction. Caesarean rate was $41.5 \%$ of which $54 \%$ were for foetal distress. $16 \%$ of neonates were admitted to NICU.

Conclusions: Based on the results of this study, we recommend universal screening of hypothyroidism in pregnancy for early 
diagnosis and treatment of this potentially treatable condition complicating pregnancy.

Copy Right, IJAR, 2019,. All rights reserved.

\section{Introduction:-}

Thyroid disorder is the second most common endocrine disorder affecting women of reproductive age and has been associated with numerous adverse pregnancy outcomes. Uncontrolled hypothyroidism during pregnancy can result in pregnancy-induced hypertension, pre-term delivery, abruption, postpartum hemorrhage, low-birth weight babies and more importantly impaired neurodevelopment in the child. Even mild or sub-clinical hypothyroidism is reported to increase the risk of impaired neurodevelopment in the offspring. Large prospective studies have shown that the maternal free thyroxin level less than $10^{\text {th }}$ percentile at 12 weeks of gestation are associated with a 6-fold increased risk of impaired neurodevelopment in infants evaluated at 10 months of age[1].

Debate about the need for universal screening for thyroid dysfunction during pregnancy is ongoing. Guidelines from American Association of Clinical Endocrinologists (AACE), the Society of Maternal-Fetal Medicine, the American College of Obstetrics and Gynecology, the Cochrane Collaboration, and the American Thyroid Association (ACA) all endorse a case finding strategy. Those who favor universal screening cite the increased prevalence of hypothyroidism during pregnancy, the inexpensive nature of the treatment, the worldwide availability of inexpensive screening test, and the cost effectiveness of a screening strategy. Those who oppose universal screening cite the paucity of evidence that identification and treatment of pregnant women with subclinical hypothyroidism improves maternal and fetal outcomes [2].

The increased prevalence of thyroid dysfunction in pregnancy and the need for proper management to reduce obstetrical and neonatal adverse events led us to collect the baseline data on hypothyroidism in pregnancy in our population.

\section{Material and methods:-}

The present study was carried out in the Department of Obstetrics and Gynecology at Dr Rajendra Prasad Government Medical College Kangra, Himachal Pradesh, India from January to December 2018 after the approval of the 'Institutional Ethics Committee' was obtained.

\section{Inclusion criteria}

All pregnant women attending the antenatal clinic of our hospital and who volunteered to participate in our study were enrolled.

\section{Exclusion criteria}

Women with known history of diabetes, collagen disorders, tuberculosis, epilepsy, multiple gestation and hypertension were excluded from the study.

\section{Methodology:-}

All the women attending antenatal clinic were sensitized about the thyroid function screening in pregnancy. The women who volunteered to participate were re-informed and queries answered by the investigators. Thereafter informed consent was obtained. The information collected included clinical details comprising demographic data, presenting complaints, obstetric \& menstrual history, symptoms suggestive of thyroid dysfunction, associated medical illness like hypertension or other cardiovascular disease, diabetes mellitus, and history of drug intake. In addition to general physical examination, local examination of thyroid gland, systemic examination, obstetrical examination were done.

Baseline investigations including hemoglobin estimation, O’Sullivan test, blood grouping and Rh typing, urinalysis, VDRL, HbsAg and HIV serology were carried out in all the women. Other investigations were done as and when required. Gestational age was determined by menstrual history, clinical examination and confirmed by USG.

All women were tested for TSH levels (determined by chemiluminescent enzyme immunoassay). Women having higher than normal range of TSH $(>2.5 \mathrm{mIU} / \mathrm{L}$ in first trimester and $>3.0 \mathrm{mIU} / \mathrm{L}$ in second trimester were further 
tested with repeat TSH \& T4. Treatment with levothyroxine was started while awaiting laboratory results. Estimation of anti TPO-antibodies was done in hypothyroid women.

Medical opinion was taken for women who were diagnosed with hypothyroidism during pregnancy. TSH was assessed 4-6 weeks after the initiation or change of levothyroxine dose. The goal of treatment was to maintain TSH level $<2.5 \mathrm{mIU} / \mathrm{L}$. Once stable, TSH was re-assed at 6-8 weeks.

During subsequent antenatal visits, maternal complications like threatened abortion, pre-term labor, and abruption, preeclampsia and any other morbidity were noted. Duration of pregnancy at the time of delivery, indication of induction \& method of induction (if required) and mode of delivery were noted. Progress of labor was monitored partographically. Detailed examination of the newborn was done. The Apgar scores at 1- minute and 5-minutes of birth, resuscitation (if required), sex, birth weight of the baby and congenital malformation (if any) were also noted. Various fetal parameters like thyroid function test (after $72 \mathrm{hrs),} \mathrm{maturity,} \mathrm{NICU} \mathrm{admission,} \mathrm{early} \mathrm{neonatal} \mathrm{death} \mathrm{etc}$ were also noted. All the mothers were advised to attend the postnatal clinic along with their babies 4-6 weeks after discharge from the hospital.

The results obtained were entered in Excel software and analyzed.

\section{Observations:}

A total of 1203 antenatal women who consented to participate were studied. Of these, 118 (9.8\%) were found to be hypothyroid.

Pregnant women with TSH value $>2.5 \mathrm{mIU} / \mathrm{L}$ in the first and $>3.0 \mathrm{mIU} / \mathrm{L}$ in the second trimester were defined as hypothyroid. The mean age of the women was $26.2 \pm 3$.7years. The age groups are shown in Table I. Most of the women (99women, 83.9\%) were from Kangra district of Himachal Pradesh. 61 women (51.5\%) were primigravida. 25 women $(21.2 \%)$ had history of previous one or more spontaneous abortions. 18 women (15.3\% women) had history of infertility. Symptoms of hypothyroidism were present in 40 women (33.9\%) as shown in Table 1. Goiter was present in 5 women $(4.2 \%)$. Mean BMI in the present study was $26.1 \mathrm{~kg} / \mathrm{m}^{2}$ (Table 1 ).

86 women (72.9\%) were diagnosed having thyroid dysfunction in current pregnancy and 32 women (27.1\%) were known cases of hypothyroidism. Duration of pregnancy at the time of diagnosis and family history of thyroid dysfunction is shown in Table 2.

Serum TSH levels, T4 levels and Anti-TPO antibody titers and gestational age at which SerumTSH became normal are shown in Table 3. Correlation between Serum TSH levels and Anti-TPO antibody titers is shown in Table 4.Antenatal complications and gestational age at the time of delivery is shown in Table 5.

Onset of labor, mode of delivery and indications of cesarean section are shown in Table 6. Apgar scores at 1-minute and 5-minute of birth, resuscitation method and early neonatal morbidity and neonatal thyroid function at 72 hours of birth are shown in Table 7.

In our study 19 babies (16\%) were admitted to NICU. 2 neonates died in early neonatal period, one because of respiratory distress syndrome and another due to sepsis, both were premature.

\section{Discussion:-}

Hypothyroidism is endemic in North India and constitutes one of the common endocrine problems. Iodine deficiency disorders are important public health problem in Himachal Pradesh. Kangra District is a known Iodine deficiency endemic area. In a survey conducted in year 2000 total goiter prevalence rate was found to be 12.1 percent [3]. In another study published in year 2007, total goiter rate was found to be 19.8 percent in this area of Himachal Pradesh [4].

Our study presents the data on hypothyroidism among pregnant women from the Sub-Himalayan region of North India. The most important finding of our study is the high prevalence of hypothyroidism (9.8\%) among pregnant women. 
In the present study the mean age of the women was $26.2 \pm 3.7$ years. In similar studies in North Indian women, the mean age was $27.6 \pm 2.9$ years [1] and $25.65 \pm 1.12$ years [5] and is similar to our study.

In the present study nearly half the women $(51.7 \%)$ were primigravida. In a study by Nuzhat et al[6], primigravidas comprised $34.1 \%$ of subjects, and in a study done by Kumar et al[7] 33.3\% were primigravidas. Poulasouchidou [8] in his study in Greece on 92 women treated for hypothyroidism found that 48 percent were nulliparous. In a large prospective study Chen M [9] observed that $80.6 \%$ women diagnosed with subclinical hypothyroidism were nulliparous.

There was history of spontaneous abortion in $21.2 \%$ women which is similar to the observations of Sharma [10] and Nambiar [11] who observed such history in $21.2 \%$ and $24.4 \%$ women respectively. Abalovich et al [12] also found that untreated hypothyroidism (subclinical or overt) at the time of conception is associated with miscarriage rate of $31.4 \%$ as compared to $4 \%$ amongst euthyroid women. Poulasouchidou [8] similarly found history of spontaneous miscarriage in 33percent women, and recurrent abortions in 9.8 percent women.

Infertility was present in $15.3 \%$ of women in this study which is nearly similar to that of Sharma [10] and Kumar [7] who found such history in $14.2 \%$ and $14.6 \%$ women respectively. Goel [1] found infertility in $17.6 \%$ of newly diagnosed hypothyroid women.

In the present study only $33.9 \%$ of women had symptoms suggestive of hypothyroidism thereby implying high risk screening (in symptomatic women) would have missed $66.1 \%$ of pregnant women with hypothyroidism. In a study by Horacek [13], 55\% of women had no symptoms and were diagnosed on routine screening. Similarly Matuszek [14] and Vaidya [15] observed that $46.4 \%$ and $30 \%$ of the studies women respectively were asymptomatic, who could have been missed by high risk screening.

We observed that only $9.3 \%$ of the women had a family history of hypothyroidism, rest $90.3 \%$ women had no such history in the family. Our observation was consistent with that of Nambiar [11] whofound family history of hypothyroidism in only $8.9 \%$ of the women.

Goiter was present only in $4.2 \%$ of women in our study, while Nambiar [11] observed goiter in $21.4 \%$ of his subjects. A survey conducted in 1956 reported a goiter prevalence of 55\% in this area of Kangra District in Himachal Pradesh, India ${ }^{3}$. Another survey conducted on school children in 2004 in this area found a total goiter rate of $19.8 \%$ [4] .Our study suggests that the population of this district is in transition phase from iodine deficient to iodine sufficient nutrition and that there is a need for further strengthening of the system of monitoring the quality of iodized salt made available to the population to eliminate iodine deficiency disorders from the Kangra Valley.

Guidelines from AACE, the Society of Maternal-Fetal Medicine, the American College of Obstetrics and Gynecology, the Cochrane Collaboration, and the ATA all endorse a case finding strategy [2]. Following their guidelines we would have missed nearly two-third cases. Our observation is corroborated by the findings of Vaidya [15] and Horacek [13] that targeted case finding will miss around 30-50\% of women with hypothyroidism. Similarly Nambiar [11] also observed that additional $60 \%$ of the hypothyroid pregnant women have been diagnosed because of universal screening only. Goel [1] stated that risk screening as recommended can miss about $32 \%$ of cases of subclinical hypothyroidism. It implies that guidelines of western literature can't be similarly reciprocated in developing countries.

In our study, there were $32(27 \%)$ women diagnosed with hypothyroidism before pregnancy and $62.5 \%$ women needed increase in the dose of thyroxine. Alexender [16] and Mandel [17] also observed increased requirement of thyroxine in 85\% and 75\% women respectively. Lazarus [18]' Yu X [19] and Albalovich [20] in their studies in newly diagnosed women used a higher dose of thyroxine to normalize maternal thyrotropin levels rapidly. In $80 \%$ to $89 \%$ women the initial dose of thyroxine did not need to be modified as pregnancy progressed $[18,19,20]$.

Most of the authors observed that hypothyroidism in pregnancy is associated with a higher incidence of Preeclampsia, pre-term labor, placental abruption, and intra uterine growth restriction [21, 22, 23]. In our study, preeclampsia was observed in $18.6 \%$ women followed by pre-term labor in $11.9 \%$, pre-labor rupture of membrane in $10.2 \%$, placental abruption in $10.2 \%$ and intrauterine growth restriction in $7.6 \%$. Nuzhat [6] found maternal complications in $39.1 \%$ women. Of these PIH was observed in $17.4 \%$ and is similar to our study. They however 
reported only one case $(.6 \%)$ of placental abruption in their series. Kumar et al [7] in their study observed that $34.28 \%$ women had pre-eclampsia and $2.8 \%$ had placental abruption. Sharma [10] found that hypothyroidism was associated with pre-eclampsia in $21.9 \%$, pre-term labor in $19.5 \%$, and threatened abortion in $14.6 \%$ and abruption in $2.4 \%$ of women. Sahu [24] also found higher association of pregnancy induced hypertension with hypothyroidism (20.7\% in overt and $13.8 \%$ in sub-clinical hypothyroidism). They also observed that intrauterine growth restriction (13.8\% in overt and $2.4 \%$ in sub-clinical) was also commonly found in pregnant women with hypothyroidism. Preterm labor (4.7\% in overt and $10.3 \%$ in sub clinical) was also found to be associated with it in their study. Goel [1] observed that gestational hypertension was significantly high in women with hypothyroidism than controls $(27.6 \%$ versus $9.8 \%)$. They found no significant difference in the incidence of gestational diabetes mellitus, intrauterine growth restriction, prematurity, anemia, postpartum hemorrhage, preeclampsia, and abruption in overt and subclinical hypothyroid groups compared to the control group.

Vaginal delivery occurred in $54.2 \%$, assisted instrumental delivery in $4.2 \%$, and cesarean section was done in $41.5 \%$ of women in our study. Out of all cesarean sections $54 \%$ were due to intrapartum fetal distress. Sharma [10] in their study found that $61.5 \%$ of cesarean sections were performed in hypothyroid women, most of them were for fetal distress; $25.6 \%$ had vaginal delivery, and $12.8 \%$ had undergone assisted vaginal delivery. Sahu [24] observed very high cesarean section rate in women with hypothyroidism (overt-52.3\%, subclinical-44.8\%), nearly half of which were due to intrapartum fetal distress (overt-36.4\% and subclinical- 53.8\%). Goel [1] observed that induction of labor was required in a significantly more women with hypothyroidism compared to controls (65\% versus $35 \%)$; cesarean section rate was not statistically significant in women with hypothyroidism and controls. The cesarean section rate in our study is comparable with available literature. Women with hypothyroidism in pregnancy needs vigilant intra-partum fetal monitoring in view of the higher prevalence of intra-partum fetal distress.

It was observed in our study that $16 \%$ of neonates got admitted in NICU. Hyperbilirubinemia was observed in $12.7 \%$ of neonates. One baby had malformation (cleft lip \& palate). There were two early neonatal deaths, one because of respiratory distress syndrome and another due to sepsis, both being premature. Nuzhat [6] found that there were $3(1.8 \%$ ) neonates with congenital anomalies (one each with polydactyly, cleft lip and renal agenesis) and $4(3.2 \%)$ neonates died in early neonatal period. Sharma [10] found neonatal hyperbilirubinemia in $13.5 \%$ of the babies. Only one baby $(2.7 \%)$ died in early neonatal period. No baby in the study group had any malformation. Sahu [24] found high incidence of neonatal complications in overt (11.1\%) and subclinical hypothyroid (12.9\%) women which included NICU admission, neonatal hyperbilirubinemia and early neonatal death. Poulasouchidou [8] found neonatal complications in $17.7 \%$ of neonates in women treated for hypothyroidism. Jaundice was observed in $8.9 \%$, RDS in $3.8 \%$, tachypnoea in $2.5 \%$, hypothyroidism in $1.3 \%$ and inguinal hernia in $1.3 \%$ of newborns. Goel [1] observed that there was no statistical difference in the incidence of fetal distress, the Apgar scores of the newborns and neonatal mortality in subclinical or clinically hypothyroid women compared to the control group. Mannisto [25] in a large cohort study in United States found that the infants born to women with thyroid disease were more likely to need NICU admission and to have higher rates of respiratory distress syndrome, transient tachypnoea, apnea, sepsis, and neonatal anemia than in neonates of women without disease.

\section{Conclusion:-}

At present there are no available recommendations for detecting or screening thyroid dysfunction among pregnant women in India. Recent western consensus guidelines do not advocate universal thyroid function screening during pregnancy but recommend testing for high risk women. Our study shows a high prevalence of hypothyroidism among sub-Himalayan North Indian pregnant women (9.8\%) with associated adverse outcomes. Based on the results of this study, we recommend universal screening of hypothyroidism in pregnancy for early diagnosis and treatment of this potentially treatable condition complicating pregnancy.

\section{Limitations:}

In our study, we screened all pregnant women with serum TSH level and subsequently offered T4 or anti TPOantibody testing when the TSH levels were abnormal. There is a possibility that this strategy could have missed women with isolated hypothyroxinemia (low T4 and normal TSH) and those who are antibody positive and euthyroid. Also the follow-up beyond early neonatal period could not be done because of time constraint.

\section{Conflict of interest:}

There is no conflict of interest. 
Table 1:-Demographic Data in Hypothyroid women

\begin{tabular}{|l|l|l|}
\hline & Number & Percent \\
\hline Age & & \\
\hline $19-25$ & 61 & 51.5 \\
\hline $25-31$ & 45 & 38.2 \\
\hline$\geq 31$ & 12 & 10.2 \\
\hline Residence & & \\
\hline Kangra District & 99 & 83.9 \\
\hline Adjoining Districts & 19 & 16.6 \\
\hline Gravidity & & \\
\hline 1 & 61 & 51.7 \\
\hline 2 & 42 & 35.6 \\
\hline$\geq 3$ & 15 & 12.7 \\
\hline Previous abortions & & \\
\hline 1 & 16 & 13.6 \\
\hline$\geq 2$ & 9 & 7.6 \\
\hline History of Infertility & 18 & 15.5 \\
\hline Symptoms suggestive of & & \\
Hypothyroidism & & \\
\hline Irregular menses & 16 & 40 \\
\hline Excessive weight gain & 9 & 22.5 \\
\hline Easy fatigability & 8 & 20 \\
\hline Chronic constipation & 3 & 7.5 \\
\hline Intolerance to cold & 2 & 5 \\
\hline Hoarseness of voice & 2 & 5 \\
\hline Goitre & 5 & 4.2 \\
\hline BMI & & \\
\hline$<18.5$ & 5 & 4.2 \\
\hline $18.5-24.9$ & 43 & 36.4 \\
\hline $25-29.9$ & 51 & 43.2 \\
\hline$\geq 30$ & 19 & 16.1 \\
\hline & & \\
\hline & & \\
\hline
\end{tabular}

Table 2:-Duration of pregnancy at the time of diagnosis and family history of thyroid dysfunction

\begin{tabular}{|l|l|l|}
\hline & Number & Percent \\
\hline Case diagnosis & & \\
\hline $\begin{array}{l}\text { Known cases of } \\
\text { Hypothyroidism }\end{array}$ & 32 & 27.1 \\
\hline Newly diagnosed & 86 & 72.9 \\
\hline $\begin{array}{l}\text { Duration of Pregnancy at } \\
\text { the time of diagnosis }\end{array}$ & & \\
\hline Before pregnancy & 32 & 27.1 \\
\hline $1^{\text {st }}$ trimester & 26 & 22.0 \\
\hline Second trimester & 54 & 45.8 \\
\hline Third trimester & 6 & 5.1 \\
\hline
\end{tabular}




\begin{tabular}{|l|l|l|}
\hline $\begin{array}{l}\text { Family history of } \\
\text { Hypothyroidism }\end{array}$ & & \\
\hline Yes & 11 & 9.3 \\
\hline No & 107 & 90.7 \\
\hline
\end{tabular}

Table 3:-TSH, T3 and T4 levels at the time of diagnosis

\begin{tabular}{|c|c|c|}
\hline & Number & Percent \\
\hline \multicolumn{3}{|l|}{$\begin{array}{l}\text { Thyroid stimulating Hormone } \\
\text { mIU/L }\end{array}$} \\
\hline $2.5-5$ & 25 & 21.2 \\
\hline $5-10$ & 60 & 50.8 \\
\hline$>10$ & 33 & 28.0 \\
\hline \multicolumn{3}{|l|}{ T4 Levels } \\
\hline $\begin{array}{l}<7.5 \mu \mathrm{g} / \mathrm{dl} \text { (cutoff for clinical } \\
\text { hypothyroidism) }\end{array}$ & 30 & 25.4 \\
\hline$\geq 7.5$ & 88 & 74.6 \\
\hline \multicolumn{3}{|l|}{ Anti-TPO Antibody } \\
\hline$\leq 35$ units & 81 & 68.6 \\
\hline$>35$ units & 37 & 31.4 \\
\hline $\begin{array}{l}\text { Gestational age at } \\
\text { normalization of TSH }\end{array}$ & Number & Percent \\
\hline$<12$ weeks & 8 & 6.7 \\
\hline 13-28 weeks & 80 & 67.8 \\
\hline 29-37 weeks & 30 & 25.4 \\
\hline
\end{tabular}

Table 4:-Correlation between TSH, T4 \& Anti TPO Antibody

\begin{tabular}{|c|c|c|c|}
\hline TSH mIU/L & Number & $\begin{array}{l}\text { T4 }<7.5 \mu \mathrm{g} / \mathrm{dl} \text { (clinical } \\
\text { hypothyroid) }\end{array}$ & $\begin{array}{l}\text { Anti TPO Antibody }>35 \\
\text { units(auto immune } \\
\text { origin) }\end{array}$ \\
\hline $2.5-5$ & 25 & 0 & $3(12 \%)$ \\
\hline
\end{tabular}




\begin{tabular}{|l|l|l|l|}
\hline $5-10$ & 60 & $1(1.6 \%)$ & $17(28.3 \%)$ \\
\hline$>10$ & 33 & $29(87 \%)$ & $17(51.5 \%)$ \\
\hline
\end{tabular}

Table 5:-Antenatal Complications and gestational age at delivery

\begin{tabular}{|l|l|l|}
\hline Complication & Number & Percent \\
\hline Pregnancy induced hypertension & 22 & 18.6 \\
\hline Preterm Labour & 14 & 11.9 \\
\hline Abruptio placenta & 12 & 10.2 \\
\hline Premature rupture of membranes & 12 & 10.2 \\
\hline Fetal growth restriction & 9 & 7.6 \\
\hline Gestational age at delivery & & \\
\hline$<37$ weeks & 14 & 11.9 \\
\hline $37-40$ weeks & 82 & 69.5 \\
\hline$>40$ weeks & 22 & 18.6 \\
\hline
\end{tabular}

Table 6:-Onset of labor, mode of delivery and indications of cesarean section

\begin{tabular}{|l|l|l|}
\hline & Number & Percent \\
\hline Onset of labor & & \\
\hline Spontaneous & 81 & 68.6 \\
\hline Induced & 23 & 19.5 \\
\hline Elective cesarean section & 14 & 11.9 \\
\hline Mode of delivery & & \\
\hline Vaginal and instrumental & 69 & 58.4 \\
\hline Cesarean & 49 & 41.5 \\
\hline $\begin{array}{l}\text { Indications of cesarean } \\
\text { section }\end{array}$ & & \\
\hline Fetal distress & 26 & 54 \\
\hline Cephalo-pelvic disproportion & 8 & 17 \\
\hline Malpresentation & 6 & 1 \\
\hline Non-progress of labor & 6 & 1 \\
\hline $\begin{array}{l}\text { Previous cesarean with } \\
\text { impending scar rupture }\end{array}$ & 1 & 2.3 \\
\hline Placenta previa & 1 & 2.3 \\
\hline Cord presentation & 1 & 2.3 \\
\hline
\end{tabular}

Table 7:-Apgar Scores, resuscitation method and early neonatal morbidity, newborns TSH level at 72 hours of birth

\begin{tabular}{|l|l|l|}
\hline Apgar score & $\begin{array}{l}\text { At 1-minute } \\
\text { Number (percent) }\end{array}$ & $\begin{array}{l}\text { At 5 minute } \\
\text { Number (percent) }\end{array}$ \\
\hline$\geq 7$ & $97(82.2 \%)$ & $116(98.3 \%)$ \\
\hline$<7$ & $21(17.8 \%)$ & $2(1.7 \%)$ \\
\hline Resuscitation method & Number & Percent \\
\hline Not required & 83 & 70.3 \\
\hline Stimulation & 13 & 11.0 \\
\hline Bag \& Mask ventilation & 16 & 13.6 \\
\hline Intubation & 6 & 5.1 \\
\hline Early neonatal morbidity & Number & Percent \\
\hline
\end{tabular}




\begin{tabular}{|l|l|l|}
\hline NICU admission & 19 & 16 \\
\hline Jaundice & 15 & 12.7 \\
\hline Neonatal death & 2 & \\
\hline Malformation & 1 & \\
\hline Baby TSH mIU/L at 72 hrs & Number & Percent \\
\hline$<5$ & 64 & 55.2 \\
\hline $5-10$ & 50 & 43.1 \\
\hline$>10$ & 2 & 1.7 \\
\hline
\end{tabular}

\section{References:-}

1. Goel P, Kaur J, Saha PK, Tandon R, Devi L. Prevalence, associated risk factors and effects of hypothyroidism in pregnancy: A study from North India. Gynecol Obstet Invest 2012; 74:89-94

2. Negro R, Stagnaro-Green A. Diagnosis and management of subclinical hypothyroidism in pregnancy. BMJ2014; 349-g4829 doi: 10.1136/mbj.g4929

3. Kapil U, Sohal KS, Sharma TD, Tandon M, Pathak P. Assessment of Iodine deficiency disorders using the 30 cluster approach in district Kangra, Himachal Pradesh. J Trop Pediatr 2000; 46(5):264-6

4. Kapil U, Sharma TD, Singh P. Iodine status and goitre prevalence after 40 years of salt iodisation in the Kangra District, India.Indian J Pediatr 2007;74(2):135-7

5. Dhanwal DK, Prasad S, Agarwal AK, Dixit V, Banerjee AK. High prevalence of subclinical hypothyroidism during first trimester of pregnancy in North India. Indian J Endoc Medtab 2013; 17:281-4

6. Nuzhat A, Pranathi R, Evita F. Hypothyroidism in pregnancy: Is universal screening needed? J Obstet Gynecol Ind 2006; 56(6):495-98

7. Kumar A, Singh R, Prasad S. Hypothyroidism during pregnancy. Int J Gynaecol Obstet 2004; 84:252-3

8. Poulasouchidou MK, Goulis DG, Poulakos P, Mintziori G, Athanasiadis G, Tarlazis BC. Prediction of maternal and neonatal outcomes in pregnant women treated for hypothyroidism. Hormones 2012; 11(4); 468-76

9. Chen L-M, Du WJ, Dai J, Zhang Q, Si G-X et al. Effects of subclinical hypothyroidism on maternal and perinatal outcomes during pregnancy: A single-centre cohort study of a Chinese population. PLoS ONE 9(10):e109364. Doi 10:10.1371/journal.phone.0109369

10. Sharma PP, Mukhopadhyay P, Mukhopadhyay A, Muraldharan PD, Begum N. Hypothyroidism in pregnancy. J Obstet Gynecol Ind 2007; 57(4):331-4

11. Nambiar V, Jagtap VS, Sarathi V, Lila AR, kamalanathan S, Bandgar TR, et al. Prevalence and impact of thyroid disorders on maternal outcome in Asian-Indian pregnant women. J Thyroid Res 2011; 2011:1-6

12. Albovich M, Gutierrez S, Alcaraz G, Maccallini G, Garcia A, Levalle O. Overt and subclinical hypothyroidism complicating pregnancy. Thyroid 2002; 12(1):63-8

13. Horacek J, Spitalnikova S, Dlabalova B, Malirova E, Vizda J, Svilias I et al. Universal screening detects twotimes more thyroid disorders in early pregnancy than high risk case finding. Eur J Endocrinol 2010; 163:645-50

14. Matuszek B, Zakoscienlna K, Basak-Radomanska E, Pyzik A, Nowakoski A. Universal screening as a recommendation for thyroid tests in pregnant women. Ann Agric Environ Med 2011 Dec; 18:375-9

15. Vaidya B, Anthony S, Bilous M, Shields B, Drury J, Hutchinson S, et al. Detection of thyroid dysfunction in early pregnancy: Universal screening or targeted high-risk case finding? J Clin Endocrinol Metab 2007; 92:2037

16. Alexander EK, Marqusee E, Lawrence J, Jarolim P, Fischer GA, Larsen PR. Timing and magnitude of increase in levothyroxine requirements during pregnancy in women with hypothyroidism. N Engl J Med 2004; 351(3):241-9

17. Mandel SJ, Larsen PR, Seely EW, Brent GA. Increased need for thyroxine during pregnancy in women with hypothyroidism. N Engl J Med 1990 Jul 12; 323(2):91-6

18. Lazarus JH, Bestwick JP, Channon S, Paradice R, Maina A, Rees R, Et al.Antenatal thyroid screening and childhood function. N Engl J Med 2012; 366:493-501

19. Yu X, Chen Y, Shan Z, Teng W, Li C, Zhow W, et al. The pattern of thyroid function of subclinical hypothyroid women with levothyroxine treatment during pregnancy. Endocrine 2013; 44:710-5

20. Abalovich M, Vazquez A, Alcaraz, Kitagrodsky A, Szuman G, Calabrese C, et al. Adequate levothyroxine doses for the treatment of hypothyroidism newly diagnosed during pregnancy. Thyroid 2013; 23:1478-83

21. Casey BM, Dashe JS, Wells CE, McIntire DD, Byrd W, Lenevo KJ, et al. Subclinical hypothyroidism and pregnancy outcomes. Obstet Gynecol 2005; 105:239-45 
22. Goel P, Radotra A, Devi K, Malhotra S, Aggarwal A, Huria A. Maternal and perinatal outcome in pregnancy with hypothyroidism. Ind J Med Sci 2005; 59(3):116-7

23. Wolfberg AJ, Lee-Parritz A, Peller AJ, Liberman ES. Obstetric and neonatal outcomes associated with maternal thyroid disease. J Matern Fetal Neonatal Med 2005 Jan; 17(1):35-8

24. Sahu MT, Das V, Mittal S, Agarwal A, Sahu M. Overt and subclinical thyroid dysfunction among Indian pregnant women and its effect on maternal and fetal outcome. Arch Gynecol Obstet 2010 Feb; 281(2):215-20

25. Mannisto T, Mendola P, Reddy U, Laughon SK. Neonatal outcomes and birth weight in pregnancies complicated by Maternal Thyroid Disease. Am J Epidemiol 2013; 178(5):731-740. 